\title{
Intercultural Teaching Approach to Integrated English Course
}

\author{
Yue $\mathrm{HU}^{1, \mathrm{a}}$ \\ ${ }^{1}$ Shanghai Normal University Tianhua College, Jiading District, Shanghai, PRC \\ a30088790@qq.com \\ *YUE HU
}

Keywords: Integrated English Course, Intercultural teaching, Classroom activities.

\begin{abstract}
This paper showcases how intercultural teaching approach could be integrated into linguistic skills training when teaching the Integrated English Course to English majors. Cases of classroom activities are presented, from which three levels of intercultural teaching could be seen, namely, harnessing intercultural sensitivity, practicing intercultural comparison and contrast ability and training students' competence to tell stories of Chinese culture. This paper also offers some suggestions for improving intercultural teaching in the classroom.
\end{abstract}

\section{Introduction}

The nexus between language and culture has already been universally acknowledged. Culture gives birth to language while language is the embodiment of culture. Language learning without decent appreciation of its cultural backdrop would definitely end up yielding meagre linguistic achievement. Thus, the consensus has been reached concerning the importance of applying intercultural approach to foreign language teaching.

Integrated English course, the core of the curriculum offered to English majors in Chinese universities, however, was traditionally preoccupied with harnessing skills only such as listening, speaking, reading, writing and translating. Teachers usually spent a tediously long span of time explaining language points, analyzing textual structures and summarizing themes for the students in class, without heeding enough attention to the culture. Teaching practice as such occurs not because teachers can't appreciate the importance of culture, but due to one widespread misconception held even by language educators that culture and language are inextricably bound together. In other words, educators assume that they automatically teach culture or even intercultural competence when they teach a language [1]. Such a skill-oriented approach, being oblivious of culture, fails to offer the panoramic picture to students within the broad category of culture, hence not only making language learning an immensely demanding task, but also failing to motivate students to the fullest extent.

Given the importance of culture in foreign language teaching, it stands to reason to take an intercultural approach when teaching this core course-Integrated English Course to the undergraduates. This paper aims at putting forward some accessible methods and suggestions for the intercultural approach to the Integrated English course.

\section{Understanding of Culture}

An appropriate intercultural approach to Integrated English course depends on the appropriate understanding of culture. Intercultural researchers tend to make a distinction between the so-called big-C culture and small-c culture.

The big-C part of a given culture embraces predominantly the factual knowledge such as literature, music, dance, painting, sculpture, theater, and film while the small-c culture consists of a wide array of inter-connected aspects, including attitudes, assumptions, beliefs, perceptions, norms and values, social relationships, customs, celebrations, rituals, politeness conventions, patterns of interaction and discourse organization, the use of time in communication, and the use of physical space and body language[2]. 
Despite the fact that some small-c cultural patterns are observable and easy to understand, the majority part of the small-c culture is convoluted and elusive because these small-c cultural aspects are imparted to native speakers from birth, thus deeply internalized and subconscious in their minds and are often noticed only when they are set in contrast with another culture. To make it even worse, it is mainly these non-tangible cultural aspects that have an enormous influence on people's way of thinking and their linguistic/non-linguistic behavior and that, importantly, determine the expectations and interpretations of other people’s linguistic/non-linguistic behavior [2].

\section{Cases of Classroom Activities}

Considering the multidimensional feature of the culture concept, the intercultural teaching in the Integrated English course should strive for building students' awareness of both the big-C culture and the small-c culture. Bearing this aim in mind, the researcher of the paper conducted one-year action research of intercultural approach in teaching Integrated English Course to a freshman class of a private college in Shanghai. The following cases of classroom activities are presented to showcase how intercultural teaching approach could be integrated into linguistic skills training in class.

The intercultural teaching is conducted mainly on the following three levels. In the first place, students are expected to acquire due cultural sensitivity because without it, students would fail to understand or even misunderstand the text. Take the phrase "grow like a beanstalk" as an example. The image of the beanstalk, which doesn't vary too much from culture to culture, will mislead students, who haven't heard of the Jack and Beanstalk fairy tale popular in the western world, into interpreting the phrase as equivalent to being overly thin. If they are trained to be sensitive enough to the cultural differences, they would realize in the western culture, growing like a beanstalk means growing very fast because that's what the magic beanstalk does overnight in the fairy tale. As can be seen from this instance, cultural sensitivity matters hugely in English learning. Therefore, teachers should call students' attention to the target culture whenever possible.

Here's one example that shows how the intercultural teaching enables students to achieve better sensitivity to culture. One of the texts says "You must first understand that the poem you write here will not be brilliant. It won't even be mediocre. But it will be better than $50 \%$ of all song lyrics and at least equal to one of Rod McKuen's best efforts". These lines don't pose too many challenges to students except for one term-Rod McKuen. Students are then given the assignment to find out who Rod McKuen is and most of them, after searching on the internet, define him as "a best-selling American poet, composer and singer, instrumental in the revitalization of popular poetry that took place in the 1960s and early 1970s". Such a definition seems to be flawless, and it seems that students have already accomplished the given task successfully. However, if we put students' definition into the original text, we would find that it collides with what the text says. How could our lousy poems be as good as the best efforts of someone who is amazingly wonderful in writing poems? When being challenged with such a question, students would soon realize that their definition, though one hundred percent true, can't account for the author's opinion properly. The factual knowledge that Rod McKuen is also called King of Kitsch, which they used to ignore, now would come to the foreground and help them understand correctly what the text truly says. Rod McKuen, the so-called King of Kitsch, though being prolific, has produced many works that are denounced as average or even mediocre. With this piece of cultural information in mind, students then could achieve better understanding of the text.

This classroom activity serves as a sound corroboration of the significance of harnessing students' cultural sensitivity. Therefore, teachers should pay enough heed to this level of intercultural teaching. By doing so, students won't take cultural knowledge for granted. Instead, they will get used to searching, selecting and ascertaining relevant Big-C cultural knowledge for achieving proper understanding of small-c cultural aspects.

Once practices that aim at training students to be sensitive to cultural differences are designed and integrated into classroom instruction, the intercultural teaching could be lifted to the second level. That is, improving students' competences to make cultural comparison and contrast. 
Here the teaching of the text "Space Invaders" will be cited to illustrate how the second level if intercultural teaching could be conducted. This text touches upon the concept of personal space, which is quite culture-specific, so the teacher firstly asked students to interview and find out Chinese people's understanding of personal space. Then students were guided by the teacher to figure out westerners' understanding of this concept based on a similar interview conducted among westerners. The comparison and contrast made between what students had obtained from their interview and conclusions they had summarized from the other interview well serves the purpose of training them to acquire the ability to see through cultural similarities and distinctions.

As students get increasingly familiar with cultural comparison and contrast patterns, students can make use of cross-cultural theories they've learned so as to make their comparison and contrast more theoretically based. For instance, after learning the text about the issue of orientation in college, students are assigned to compare and contrast orientation procedures in Chinese universities and American universities and delve into the root causes of these cultural differences. By doing so, students not only are more at ease with cross-cultural theories such as collectivism vs. individualism, formality vs. informality, high vs. low face concerns, so on and so forth, but also learn to appreciate cultural differences with perception and penetration.

Once the ability to tell the cultural differences is acquired, students can be led to move onto the third level — telling Chinese stories to the western world. Such ability is desirable currently as China is eager to embrace the world more fully than before. It's true that linguistic abilities are crucial in determining the quality of the traditional Chinese stories, but cross-cultural competence is also something we can't afford to overlook.

Here the teaching plan of the text "My forever Valentine" is cited as a case in point.

The text is about Valentine's Day, a typical cultural concept. Besides explaining the origin of this western holiday to students, the teacher also intends to lead students into better understanding of its Chinese counterpart, namely, the Double Seventh Day. Therefore, after showing how we can tell story about the origin of the western holiday, the teacher designed a classroom activity in which students were required to find out how the Double Seventh Day came into being in China historically and role-played their story version in class. When they did the role-play, their foreign teachers would be invited as the judgers.

There are several rationales for this teaching design. To start with, students are expected to practice their abilities for searching, analyzing and synthesizing information they have obtained from various sources. In order to present a well-received role-play, they should carefully plan how to reorganize the materials.

Secondly, the team work requires team spirit. Students should learn to cooperate in a group and assign different duties to different team members so as to make the team work harmoniously. Some students are good at performing while others excel at preparing script. How to allot tasks to capable students is the key to maximize the potential of group work.

More importantly, students learn how to properly and idiomatically introduce Chinese culture, in particular to foreigners who don't necessarily have background information about the topic. It's not difficult at all to role-play Chinese stories to Chinese students and teachers because they're already familiar with the culture. However, things are becoming immensely herculean if the target audience includes foreigners. Students have to figure out appropriate way of introducing the Chinese culture, that is acceptable and comprehensible to these foreigners.

\section{Conclusion}

What we promote here is a more complex and enriched understanding of language teaching. It's a widely known fact that language teaching can't be reduced to linguistic skills training only [2]. Therefore, the intercultural teaching approach is of great significance to foreign language teaching in today's world. However, as put by Zhang Hongling in her work, due to lack of in-depth understanding of intercultural teaching, when implementing intercultural teaching in classroom, teachers are concerned with factual knowledge while ignoring the cultivation of intercultural competence, which debilitates severely students’ foreign language acquisition process[3]. 
As the core course that aims at helping students adjust themselves from the exam-orientation education in high school to university study where the area of study is more focused and specialized, the Integrated English Course is both an extension of language learning of high school and a new starting point for more specialized learning in college [4]. By incorporating intercultural approach into language teaching in the classroom of the Integrated English course, we are blessed with a new perspective of improving linguistic skills and intercultural competence of students at the same time.

\section{References}

[1] M. Byram, M. Wagner, Making a difference: Language teaching for intercultural and international dialogue, Foreign Language Annals. 51 (2018) 140-151.

[2] Z. Chlopek, The Intercultural Approach to EFL Teaching and Learning, English Teaching Forum. 4(2008) 10-19.

[3] H.L. Zhang, Intercultural Approach to Foreign Language Teaching, Shanghai Foreign Language Education Press, Shanghai, 2007.

[4] X.Q. Fu, H.L. Zhang, The Design and Practice of Intercultural Teaching in Integrated English Course, Foreign Language World. 178 (2017) 89-95. 